\title{
Quiste mesentérico mesotelial. Reporte de caso
}

Mesothelial mesenteric cyst. Case report

José Enrique Torres ${ }^{1}$

ORCID https://orcid.org/0000-0003-2231-5268

Gonzalo Perrone Arballo ${ }^{2}$

ORCID https://orcid.org/0000-0001-6943-8754

Martín Salvatierra ${ }^{3}$

ORCID https://orcid.org/0000-0002-8842-1779

DOI $10.31837 /$ cir.urug/5.2.5

Recibido: 9 de noviembre de 2020

Aceptado: 5 de abril de 2021

\section{Resumen:}

Los quistes mesentéricos son tumoraciones abdominales infrecuentes. Su incidencia es de 1/100.000 en adultos, pueden comprometer cualquier sector del mesenterio, siendo más frecuente en el íleon. Generalmente son benignos y su patogénesis se desconoce. Su diagnóstico preoperatorio es complejo ya que la presentación clínica es variable. Generalmente son asintomáticos presentándose como un hallazgo incidental. Los síntomas son secundarios al tamaño o sus complicaciones. Su tratamiento es quirúrgico mediante la exéresis de la lesión. El diagnóstico definitivo es anatomopatológico. Presentamos el caso de un quiste de mesocolon derecho resuelto exitosamente por abordaje laparoscópico.

Palabras claves: Quiste mesentérico-Quiste mesocolon-Abordaje laparoscópico.

1,2,3 Hospital Regional Salto. Salto - Uruguay.quiquetorres31@ hotmail.com

\section{Abstract}


Mesenteric cysts are rare abdominal tumors. Its incidence is $1 / 100,000$ in adults. It can compromise any sector of the mesentery, being more frequent in ileon. They are usually benign, and their pathogenesis is unknown. Its preoperative diagnosis is difficult as clinical presentation is variable. They are usually asymptomatic presenting as an incidental finding. Symptoms are secondary to size or complications. Its treatment is surgical by exeresis of the injury. The definitive diagnosis is anatomopathological. We present the case of a right mesocolon cyst successfully resolved by laparoscopic approach.

Keywords: Mesothelial cyst- Mesocolon cyst- Laparoscopic approach.

\section{Caso clínico:}

Paciente de sexo femenino, 42 años, consulta por cuadro de 15 días de evolución dado por dolor abdominal localizado en flanco y fosa ilíaca derecha, de intensidad creciente. Presenta náuseas, sin vómitos, apirética. Al examen presenta dolor a la palpación de hemi-abdomen derecho donde impresiona tumoración tensa y móvil.

Como resultados de los análisis clínicos se destaca: Hemograma 12000 GB, BHCG negativa y examen de orina normal.

La ecografía abdominal arroja como resultado: imagen anecogénica, polilobulada, por delante del polo inferior del riñón derecho, paredes finas, de $62 \times 41 \mathrm{~mm}$.

Se indica una Tomografía Computada de abdomen y pelvis con contraste intravenoso: se confirma imagen descrita. No presenta relaciones vasculares relevantes ni invasión de estructuras vecinas. (fig. 1).

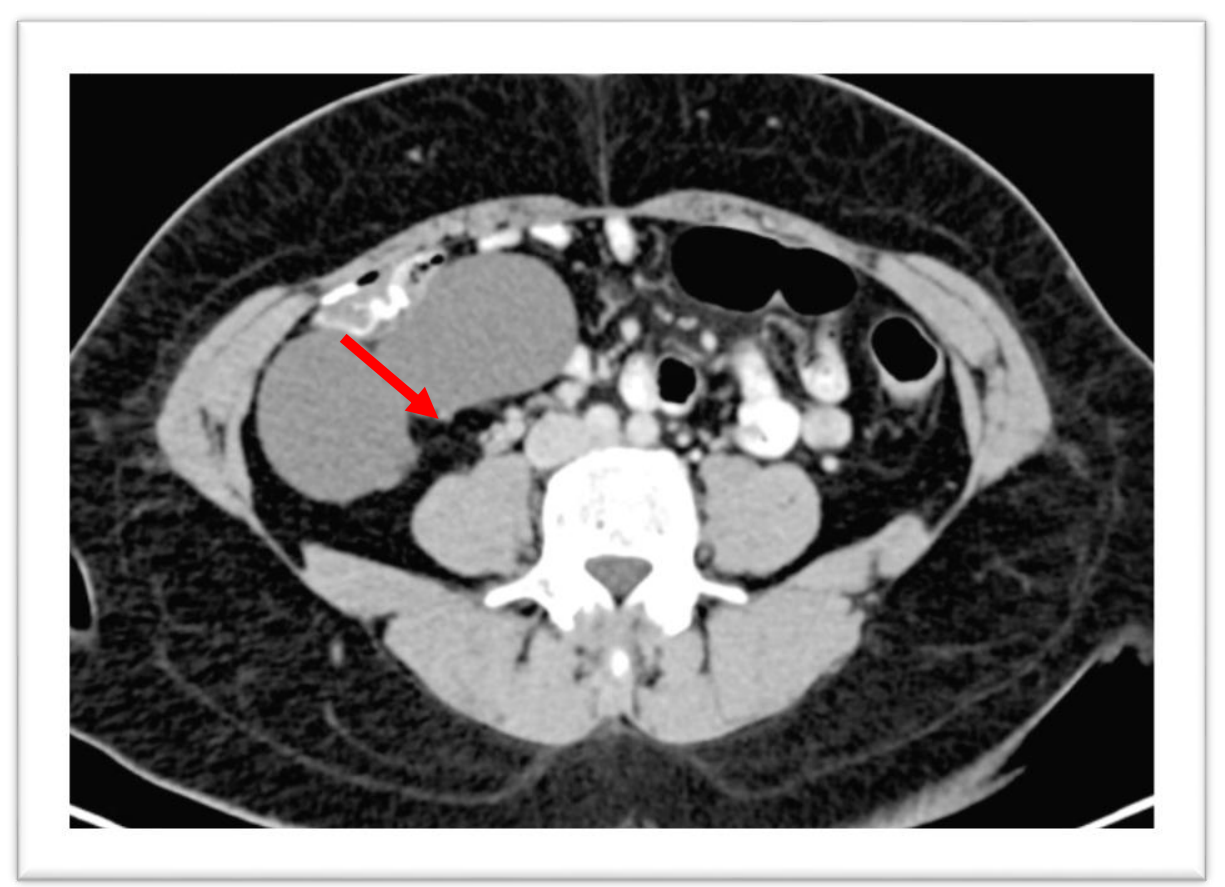

Fig 1: Corte axial de tomografía computada de abdomen. Imagen quística polilobulada (flecha). 
La Resonancia Nuclear Magnética presenta estos resultados: lesión quística con las características mencionadas Presenta tabiques finos, sin componente sólido. Mide 10 × $5 \mathrm{~cm}$ de diámetro mayor. Contacta lateralmente con el colon sin comprometer sus vasos. Probable origen mesentérico (Fig. 2).

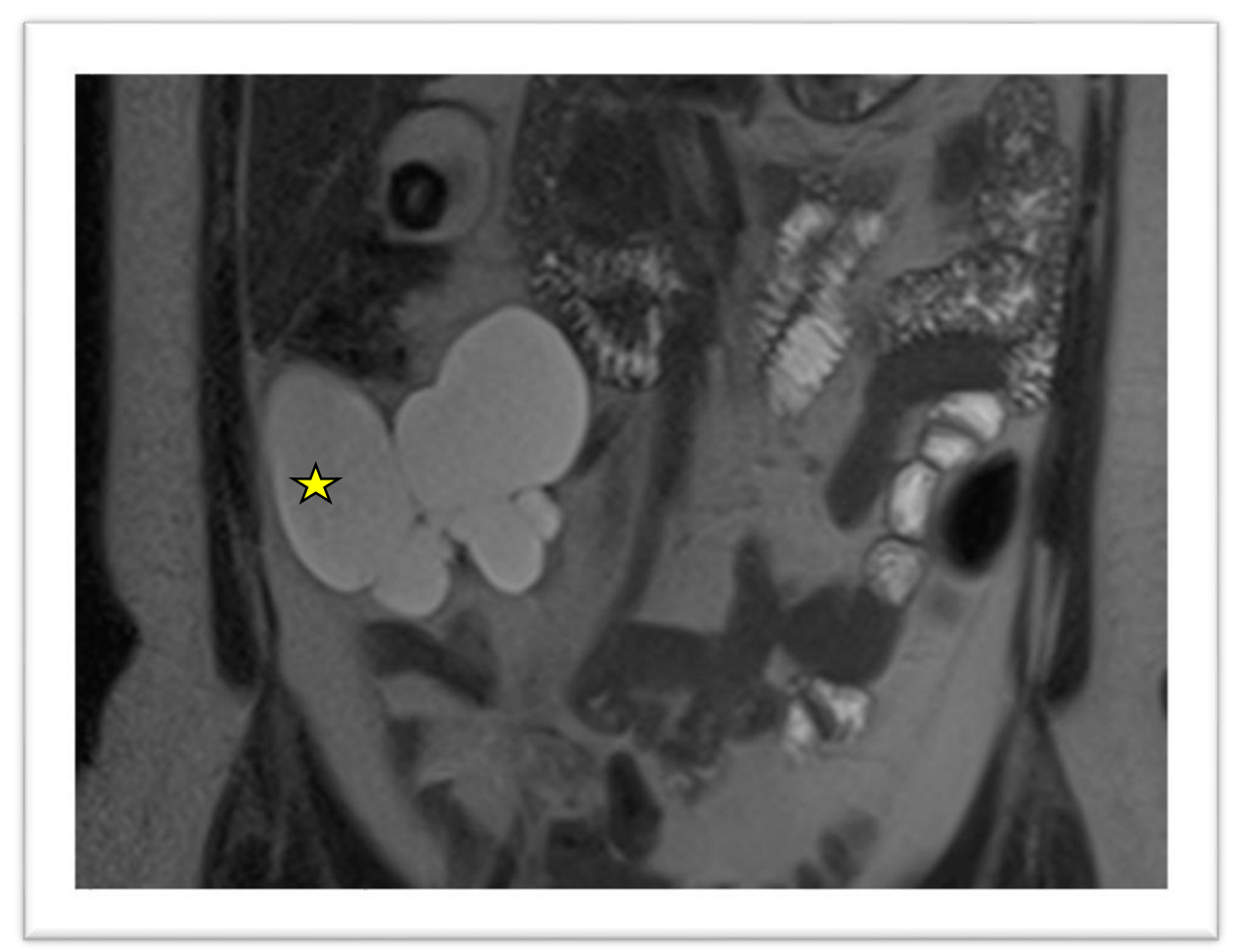

Figura 2: Corte coronal de Resonancia Nuclear Magnética: imagen polilobulada quística en contacto con colon ascendente. (Estrella)

Se realiza laparoscopía exploradora. Se identifica una lesión quística en mesocolon ascendente (Fig. 3). Se realiza enucleación del quiste seccionando el meso con bisturí armónico y liberación de éste con maniobras romas, se coloca en bolsa y se evacúa para extracción por incisión de Pfannenstiel. 


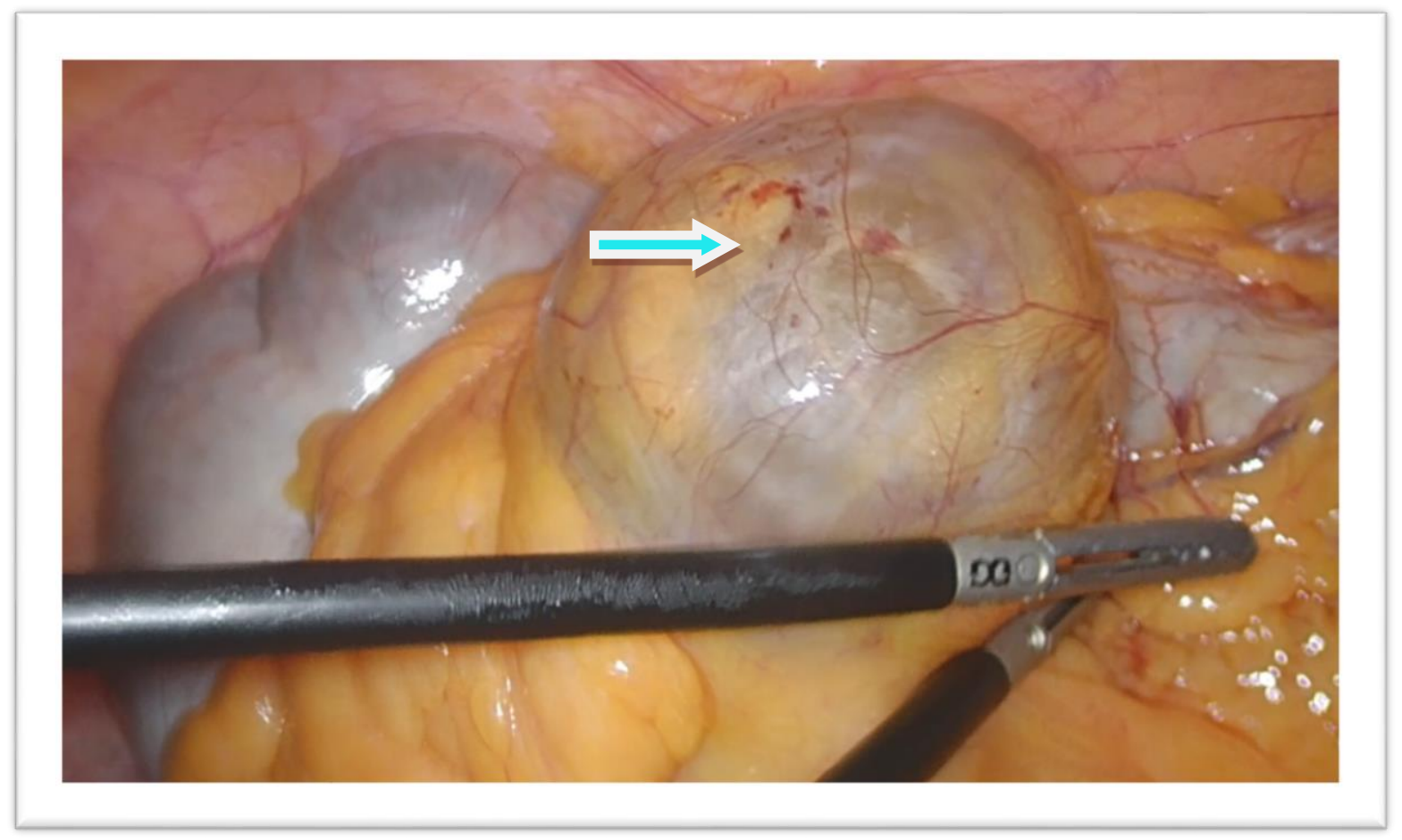

Figura 3: Emergencia lateral interna del quiste (flecha)

El resultado de la Anatomía patológica indica: Citología negativa para malignidad.Lesión quística de revestimiento mesotelial plano con tabiques fibrosos adheridos a tejido adiposo vecino, sin infiltración. Sin elementos de malignidad.

En suma: Quiste mesotelial simple de mesenterio.

Presenta buena evolución postoperatoria. Se da de alta a las 48 hs. No ha presentado recidiva a los 5 meses de seguimiento.

\section{Discusión}

El diagnóstico clínico preoperatorio de los quistes mesentéricos es dificultoso. Los síntomas dependen de la ubicación, el tamaño y la presencia de complicaciones como hemorragia intra quística, infección, ruptura o torsión. La ecografía abdominal evidencia una tumoración quística hipoecogénica de pared fina y bien delimitada. El engrosamiento o calcificación de la pared hace referencia a una lesión estable. La tomografía computada y la resonancia nuclear magnética mejoran la visualización de la relación con estructuras vasculares y otros órganos en vistas a la cirugía. En cuanto a los posibles diagnósticos diferenciales: quiste hidatídico, pseudoquiste pancreático, ascitis loculada (generalmente tuberculosa), quiste omental, quiste de duplicación entérica, mesotelioma quístico, quiste de ovario, quistes urogenitales. La presencia de malignidad debe ser considerada también como diagnóstico diferencial. 
Existen reportes de transformación maligna de quistes benignos en un 3\%. La presencia de una pared gruesa o nódulos eleva la sospecha de neoplasia maligna. Esto justifica la solicitud de imágenes para su detección y tratamiento precoz una vez diagnosticado ${ }^{1}$.

Clásicamente el manejo del quiste mesentérico sintomático es su exéresis de urgencia. En ocasiones se realiza su marsupialización para evitar una resección intestinal extensa, aunque el riesgo de recidiva es mayor. El drenaje quirúrgico se evita debido a la infección y alta tasa de recurrencia. El enfoque conservador en la presentación aguda seguido de cirugía electiva puede ser un enfoque seguro. Éste debe reservarse para pacientes estables sin síntomas de obstrucción intestinal, isquemia intestinal, uropatía obstructiva, vólvulo o peritonitis ${ }^{2}$.

El tratamiento de elección es la escisión quirúrgica completa mediante la enucleación del quiste con disección roma, existiendo complicaciones intraoperatorias como son, sangrado por lesión vascular del meso, lesión visceral, contaminación peritoneal por rotura del quiste. La escisión completa presenta menor tasa de recurrencia en comparación con el drenaje simple o la marsupialización las cuales se reservan en caso de adherencias del quiste a órganos vecinos o localización profunda en la raíz del mesenterio. Existen reportes de ablación percutánea con etanol y contracción secundaria de la lesión, pero con resultado variable ${ }^{3-4}$.

El abordaje puede ser laparotómico o laparoscópico. La indicación debe ser individualizada en función del tamaño, relaciones del quiste y experiencia del cirujano. La exéresis laparoscópica representa una alternativa segura y menos invasiva por lo cual debe ser considerada como primera opción, dado que presenta resultados similares a la laparotomía con menor dolor postoperatorio, menor estadía hospitalaria 5 .

A modo de conclusión los quistes mesentéricos son una afección poco frecuente, representan un desafío diagnóstico y deben considerarse cuando estamos frente a una masa quística intraabdominal. Si ésta es sintomática la escisión quirúrgica completa se considera la intervención de elección. El abordaje laparoscópico es factible presentando menor comorbilidad y estadía hospitalaria en comparación con la cirugía abierta.

\section{Bibliografía}


1-Yavuz Y, Varman A, Şentürk Ü, Kafadar M. Mesenteric Cyst in 22 Cases. J Gastrointest Cancer. 2020 doi.10.1007/s12029-020-00522-9

2-Leung B, Sankey R, Fronza M, Maatouk M. Conservative approach to the acute management of a large mesenteric cyst. World J Clin Cases. 2017;5(9):360-3. doi: 10.12998/wjcc.v5.i9.360

3-Carvalho N, Lopes Filho J, Plens I, Camara V, Teixeira C, Figueiredo P et al. Mesenteric cyst presenting with acute abdomen pain and bowel obstruction: Case report and brief literature review. Ann Med Surg. 2020; 58:134-7. doi: 10.1016/j.amsu.2020.09.001.

4-Pozzi G, Ferrarese A, Borello A, Catalano S, Surace A, Marola S et al. Percutaneous drainage and sclerosis of mesenteric cysts: Literature overview and report of an innovative approach. Int J Surg. 2014; 12:90-3. doi: 10.1016/j.ijsu.2014.08.372

5-Bono D, Tomaselli F, Caponi R, Saracco R. Laparoscopic excision of a voluminous mesenteric cyst: case report of a rare entity and review of literature. Int J Surg Case Reports. 2020; 77S(Suppl):S64-S66. doi: 10.1016/j.ijscr.2020.10.042. 